\title{
The bone marrow in aplastic anaemia: Diagnostic and prognostic features
}

\author{
B. FRISCH AND S. M. LEWIS
}

From the Department of Haematology, Royal Postgraduate Medical School, Hammersmith Hospital, London

SYNOPSIS Bone marrow preparations were examined from 80 patients with aplastic anaemia. The degree of cellularity varied greatly and in a third of the cases it was normal or even hypercellular at one site of aspiration. In the severely hypoplastic marrows lymphoid cells were predominant and this situation was associated with a worse prognosis. There was no correlation between marrow lymphoid cell content and blood lymphocyte count but there was an inverse relationship between blood lymphocyte count and marrow erythroblasts and a close direct relationship between the blood neutrophil count and marrow myeloid cell content.

In all cases a proportion of the erythroblasts showed morphological abnormalities. These included especially megaloblastic changes and asynchrony of nuclear-cytoplasmic maturation. There were also binucleated cells, internuclear chromatin bridges, intercellular cytoplasmic connexions, nuclear degenerative changes, namely, blurred outlines, irregular shapes, budding and fragmentation, and atypical mitotic figures. These appearances illustrate the extent to which a qualitative defect of erythropoiesis occurs as part of the haematological pattern in aplastic anaemia, and in some cases dominates the bone marrow picture.

Similar cytological features were found in all cases, including five patients with Fanconi's anaemia.

Haematopoiesis is affected in two ways in aplastic anaemia. In addition to a quantitative decrease in haematopoeitic cells, there are qualitative alterations. In the mature neutrophil this is manifested by the presence of abnormally dark red-staining granules in Romanowsky-stained films and by exceptionally high alkaline phosphatase (Lewis, 1962). In the erythroid cells it results in the production of a proportion of defective cells; these are characterized by morphological abnormalities such as poikilocytosis and fragmentation, decreased survival in vivo (Lewis, 1962), and increased sensitivity to lysis by anti-I in vitro due to enhanced uptake of antibody (Lewis, Grammaticos, and Dacie, 1970). These features indicate that dyserythropoiesis is a characteristic of the aplastic anaemias, albeit usually overshadowed by the hypoplasia. The purpose of this study was to review bone marrow appearances in aplastic anaemia in order to assess the extent of dyserythropoiesis and to evaluate the use of bone marrow cytology as a guide to prognosis.

Received for publication 12 November 1973.

\section{Materials and Methods}

A total of 100 bone marrow aspirates was examined from 80 patients. The patients had been diagnosed as suffering from aplastic anaemia on the results of peripheral blood counts and bone marrow biopsies, their clinical course, and, in some cases, postmortem findings. Many of the patients have been included in previous reports on other aspects of aplastic anaemias (Lewis, 1962, 1965, 1969; Lewis and Dacie, 1967). In 51 of the cases a drug or chemical may have been incriminated, namely, chloramphenicol (11), other antibiotics (8), phenylbutazone (9), gold (3), industrial solvents (6), insecticides (2), tranquillizers (3), analgesics (7), other drugs (6), $x$-rays (2). In 37 of the cases more than one toxic agent may have been implicated. In other cases no possible aetiological agent was identified.

Of 13 children included in the series, five were diagnosed, on the basis of family history and/or characteristic physical stigmata, as having Fanconi's anaemia. Patients with pure red cell anaemia have not been included. 
Bone marrow was aspirated from the sternum or iliac crest, using a Salah needle, into a syringe without anticoagulant. Drops of the aspirate were placed onto glass slides, excess blood was sucked up by means of a Pasteur pipette, and the residual material, which included marrow fragments visible when present as semitranslucent specks, was spread on the slides. After air-drying the slides were fixed in methanol and stained with May-Grünwald Giemsa's stain by a standard method (Dacie and Lewis, 1968).

The films were examined by light microscopy and the following observations were made:

DEGREE OF CELLULARITY

This was graded 1-6 as follows:

\section{Grade 1}

Although material was undoubtedly of marrow origin, as evidenced by the presence of isolated reticulum cells, phagocytes, mast cells, and scattered haemopoeitic cells, there were no fragments and no organized cellularity.

\section{Grade 2}

Fragments of fatty tissue containing phagocytes and reticulum cells with a small amount of haemopoietic tissue in the fragments and in the trails.

\section{Grade 3}

Some haemopoietic tissue in trails and in the main body of the film.

\section{Grade 4}

Fragments present; normal cellularity within the fragments and in the trails.

\section{Grade 5}

Normal numbers of fragments with moderately increased cellularity.

\section{Grade 6}

Hypercellular, often with abundant fragments.

\section{CELL POPULATIONS}

In 25 cases selected at random, the relative distribution of erythroid, myeloid, and lymphoid cells was estimated from a count of 500 nucleated cells in each marrow preparation; with markedly hypocellular preparations it was necessary to scan more than one smear of the same aspirate to reach the required count. The ratio of myeloblasts + promyelocytes: myelocytes + metamyelocytes was also estimated. The presence of cells other than those listed above was also noted: these included megakaryocytes, reticulum cells and connective tissue cells, phagocytes with and without cellular debris, mast cells, basophils, plasma cells, and monocytes.

\section{MORPHOLOGY OF ERYTHROID CELLS}

The erythroblasts were classified as follows: $(a)$ normal early erythroblasts, ie, up to polychromatic stage; (b) normal late erythroblasts, ie, haemoglobinized cells; (c) abnormal early erythroblasts; (d) abnormal late erythroblasts.

The morphological criteria for abnormality were as follows: asynchrony of maturation between nucleus and cytoplasm, mitotic abnormalities, binuclearity or multinuclearity, nuclear lobulation, budding, fragmentation, internuclear bridging, and megaloblastosis. These abnormalities are characteristic of dyserythropoiesis (Lewis and Verwilghen, 1973). Cytoplasmic vacuolation, basophilic stippling of the cytoplasm, and cytoplasmic connexions between erythroid cells were also taken to indicate dyserythropoiesis.

For scoring the percentage of abnormal (dyserythropoietic) cells, any erythroblast showing one or more of the above features was classified as being abnormal. Five hundred erythroblasts were examined in each case.

\section{Results and Observations}

\section{MARROW CELLULARITY}

The cellularity of the aspirated marrows varied considerably. In 76 marrows (61 patients) the marrow was hypocellular (grades 1-3) whereas in 46 marrows (30 patients) it was normal (grade 4) or even hypercellular (grades 5-6). In several of the cases the cellularity of a second aspirate differed from that of the first; such variability might occur within a small area of marrow (fig 1). The peripheral blood cytopenia usually but not always paralleled the degree of bone marrow hypoplasia (as revealed at the site of one aspiration).

\section{MARROW CELL POPULATIONS}

The myeloid:erythroid (M:E) ratio ranged from $0 \cdot 23: 1$ to $15: 1$, with a mean of $2 \cdot 19$ (SD 3.40) (normal range $2 \cdot 5-15: 1$ ).

The myeloid:lymphoid (M:L) ratio ranged from $0 \cdot 13: 1$ to $5 \cdot 8: 1$ with a mean of $1 \cdot 54$ (SD 1.68) (normal range $1 \cdot 0-17: 1$ ).

The lymphoid:erythroid (L:E) ratio ranged from $0 \cdot 13: 1$ to $16 \cdot 7: 1$ with a mean of $3 \cdot 18$ (SD 4.63) (normal range $0 \cdot 2-4: 1$ ).

The mean distribution of the three groups was:

\begin{tabular}{lccccc}
\hline & $M$ & $:$ & $L$ & $:$ & $E$ \\
\hline & $28 \%$ & $:$ & $34 \%$ & $:$ & $38 \%$ \\
SD & 17 & & 17 & 19 \\
SE & 3.7 & & 4.0 & & 4.1 \\
\hline
\end{tabular}



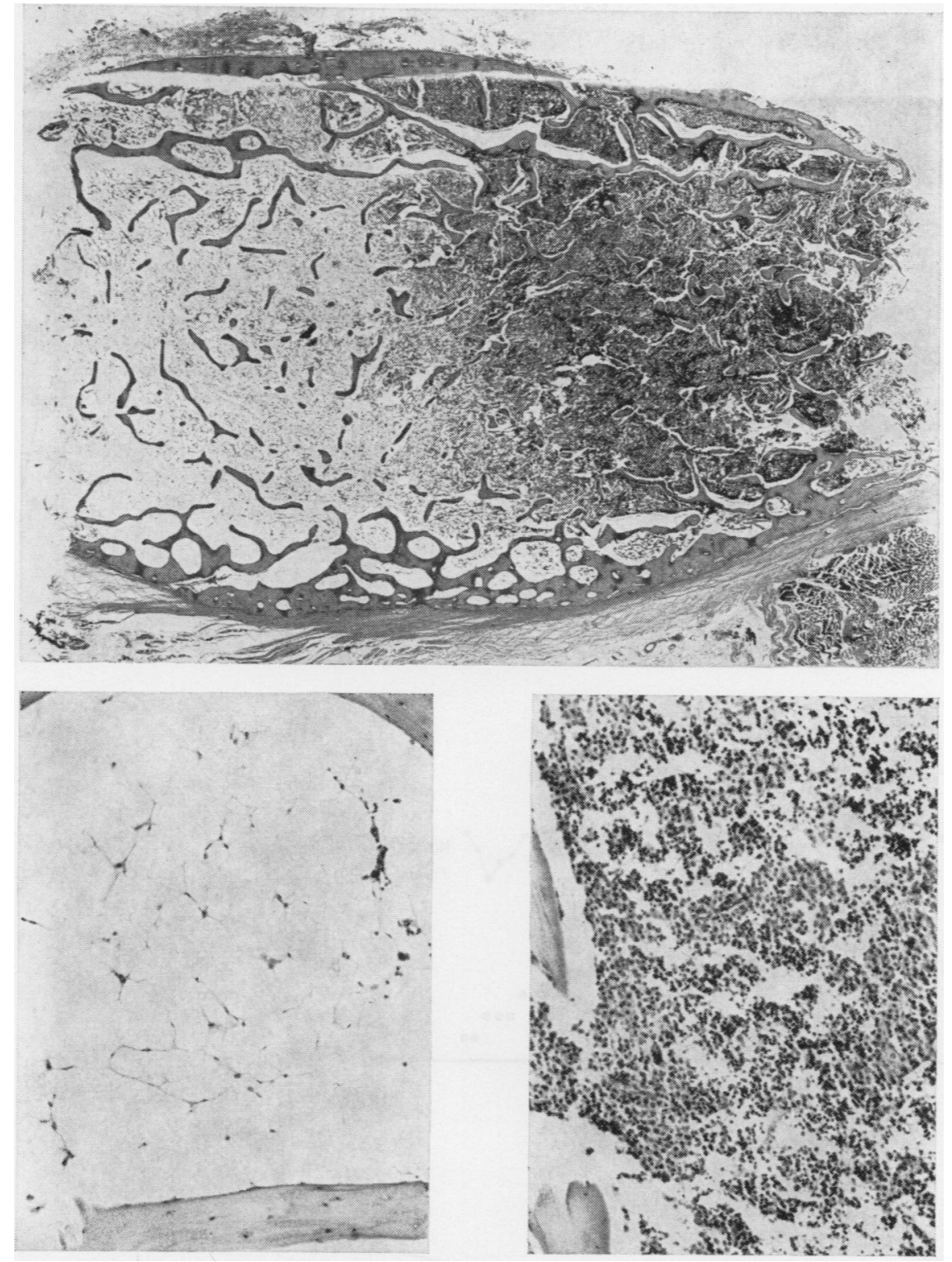

Fig 1 Section of sternum obtained after death from a case of aplastic anaemia. There is marked variability in bone marrow cellularity: on the right hand side there is an area of marked hyperplasia. H. \& E. stain; upper photograph $\times 20$, lower photographs $\times 100$.

The predominant cell type varied between cases. In some there was a normal relative distribution. In many cases, however, especially in the more severe hypoplasias, lymphoid cells were predominant (figs 2 and 3), and there was an inverse correlation between lymphoid and erythroid cells (fig 3 ).

As a rule there was a normal relative distribution of myeloid cells. Myeloblasts comprised 1-5\%, usually $1-2 \%$. Means and SD of the other cells were: myelocytes $16.9 \%( \pm 4.8)$, metamyelocytes $23.2 \%( \pm 7 \cdot 7)$, polymorphs $30.5 \%( \pm 9 \cdot 8)$. In about half the cases, however, the ratio of blasts and promyelocyte:myelocytes and metamyelocytes, normally $1: 5$ to $1: 10$ was reduced to about $1: 3$. 


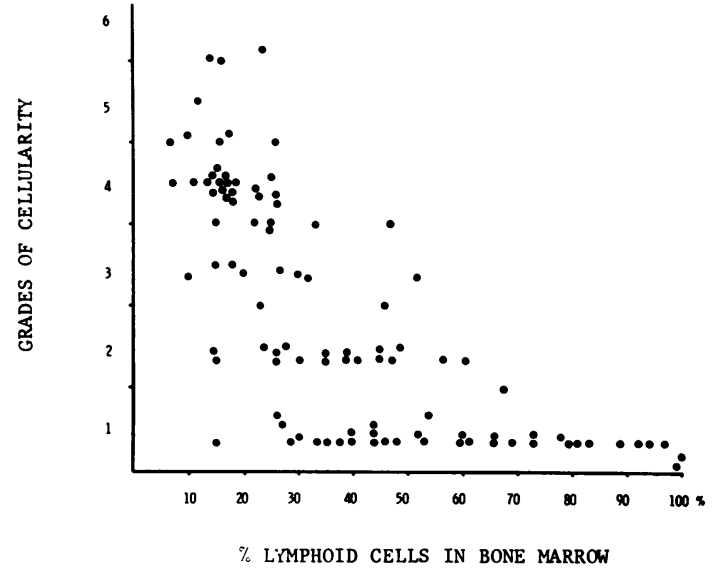

Fig 2

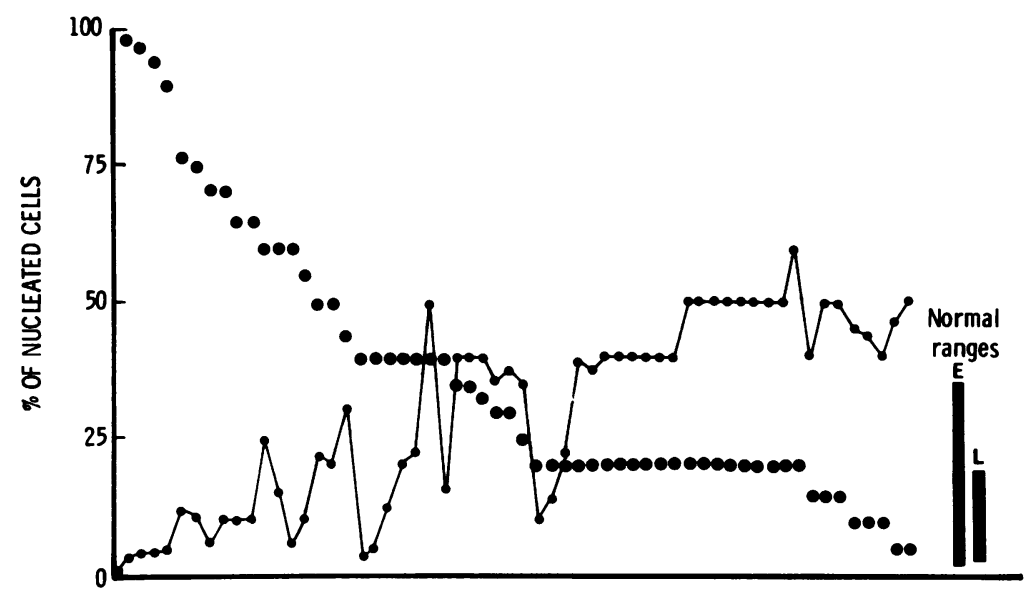

Fig 3

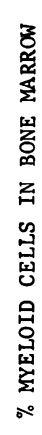

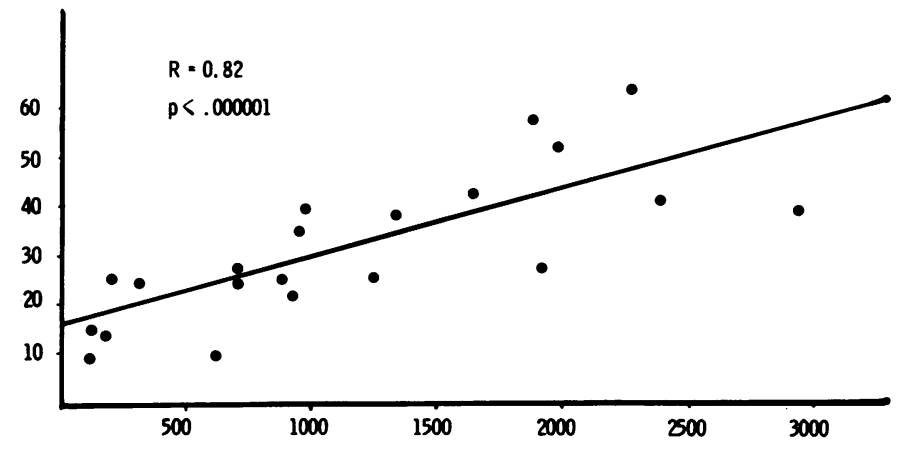

Fig 4
Fig. 2 Occurrence of lymphoid cells in bone marrow related to cellularity. The grades of marrow cellularity are described in the text; grade 1 is the most markedly hypocellular and grade 6 is hypercellular.

Fig 3 Proportional relationship of lymphoid cells to erythroblasts in the bone marrow in aplastic anaemia. The lymphoid cells $(L)$ are indicated by large dots; the erythroid cells $(E)$ by the dots which are joined with the continuous line. All grades of marrow cellularity are included.

Fig 4 Relationship of bone-marrow myeloid cells to peripheral blood neutropenia in aplastic anaemia. 


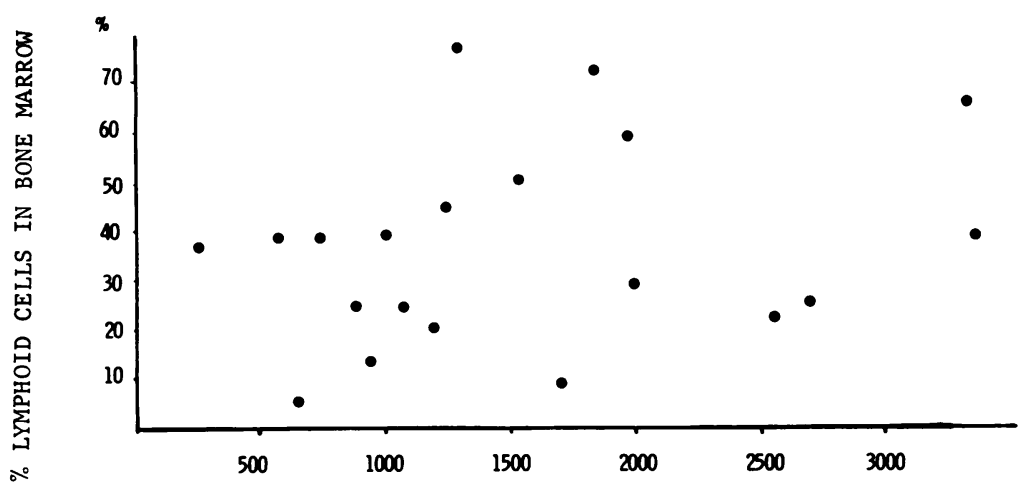

Fig 5

BLOOD LYMPHOCYTE COUNT $(/ \mu 1)$

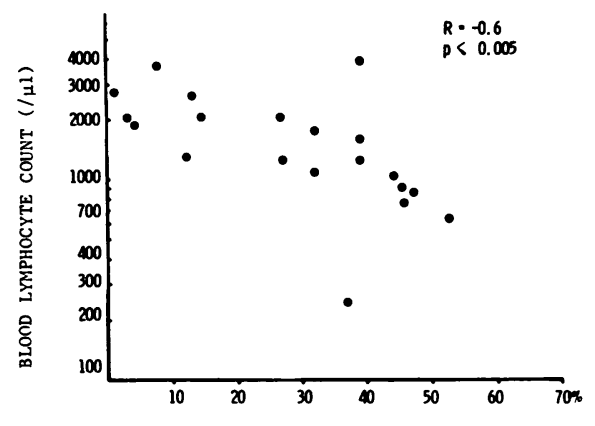

Fig 5 Relationship of bone-marrow lymphoid cells to blood lymphocyte count in aplastic anaemia.

Fig 6 Relationship of bone-marrow erythroblasts to blood lymphocyte count in aplastic anaemia.

Fig 6

The relationship of cell type predominating in the bone marrow to the peripheral blood leucocyte count was studied. Not unexpectedly, a high relative myeloid cell content in the marrow was associated with a less severe degree of neutropenia and the correlation was remarkably close $(r=0.8)$ (fig 4). On the other hand, there was no correlation between bone marrow lymphoid cells and blood lymphocyte count (fig 5). There was, however, an inverse relationship between blood lymphocyte count and marrow erythroblast percentage (fig 6).

The prognosis was related to some extent to the peripheral blood neutrophil and platelet counts; patients with platelet counts of less than $10,000 / \mu 1$ and neutrophils less than $600 / \mu 1$ rarely survived longer than six months. The blood lymphocyte count did not bear a similar direct relationship to prognosis. However, a high proportion of lymphoid cells in the marrow appeared to indicate a grave prognosis.

In the children with Fanconi's anaemia the pattern of bone marrow cytology was similar to that in cases of acquired aplastic anaemia.

\section{'Reticulum cell'}

Under this heading are included phagocytes and connective tissue cells. These were present in all hypoplastic marrows, frequently in association with mast cells (fig 7), and they were seen in both acquired and congenital aplastic anaemia. Many of the phagocytes contained cellular debris, especially in the more cellular marrows, and phagocytes containing numerous vacuoles were also observed (fig 8). In some instances plasma cells were present in groups and some could be seen in apposition to a capillary (fig 9).

\section{Megakaryocytes}

Megakaryocytes 'were not generally to be found in hypocellular marrows of grades 1 and 2 . Nonetheless, platelets were frequently seen in these smears, an indication that megakaryocytes were not completely 
B. Frisch and S. M. Lewis

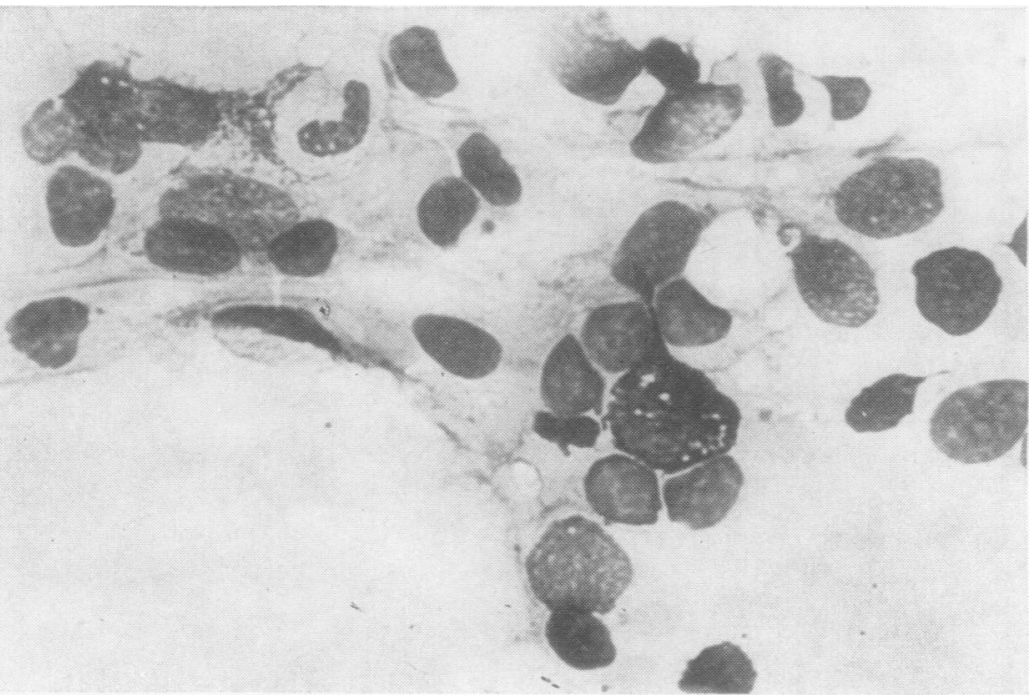

Fig 7 Photomicrograph of hypoplastic marrow showing reticulum cells and mast cell $\times 800$.
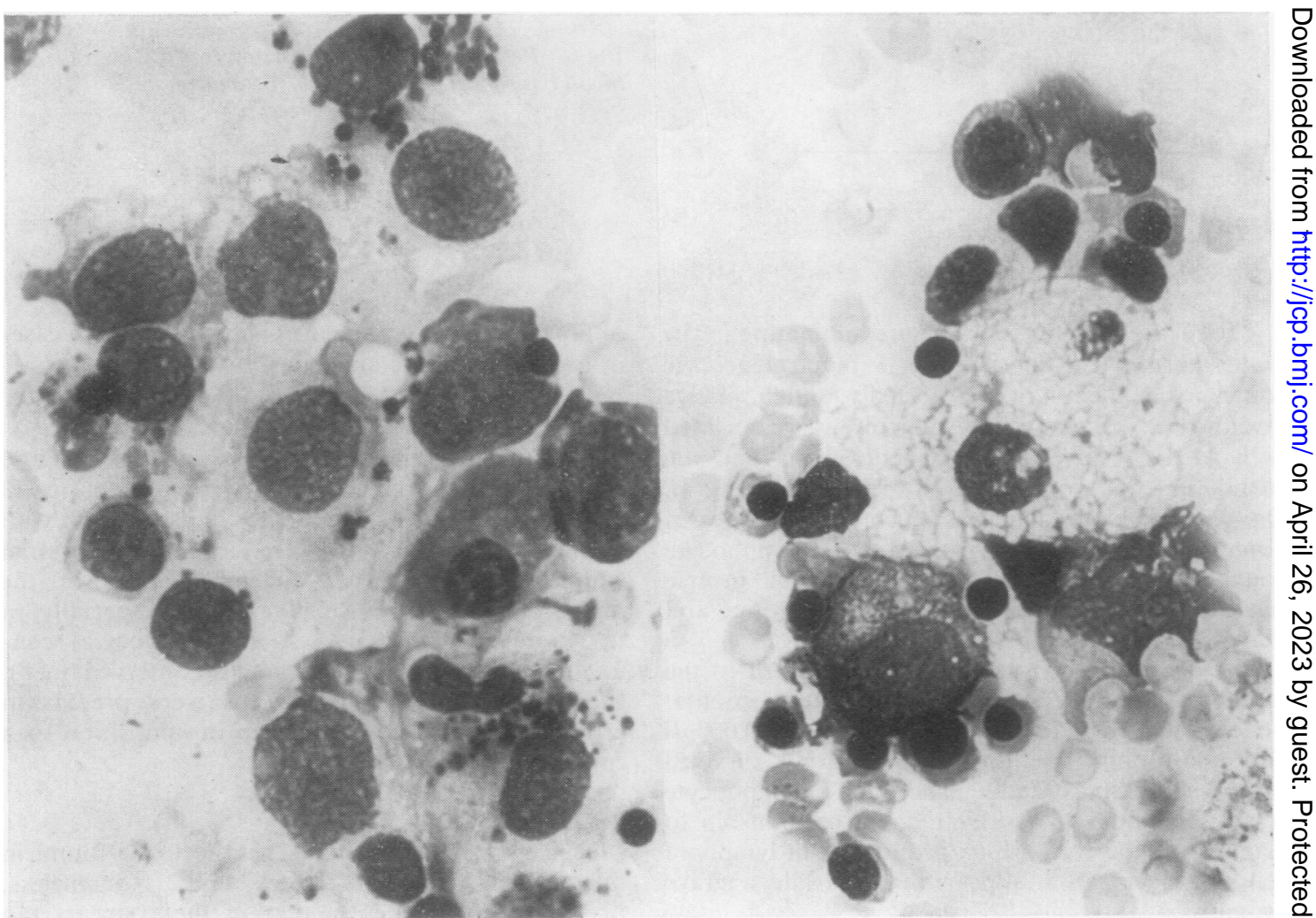
Fig 8 Photomicrographs of bone marrow from patient with aplastic anaemia showing presence of phagocytes $\times 800$. 


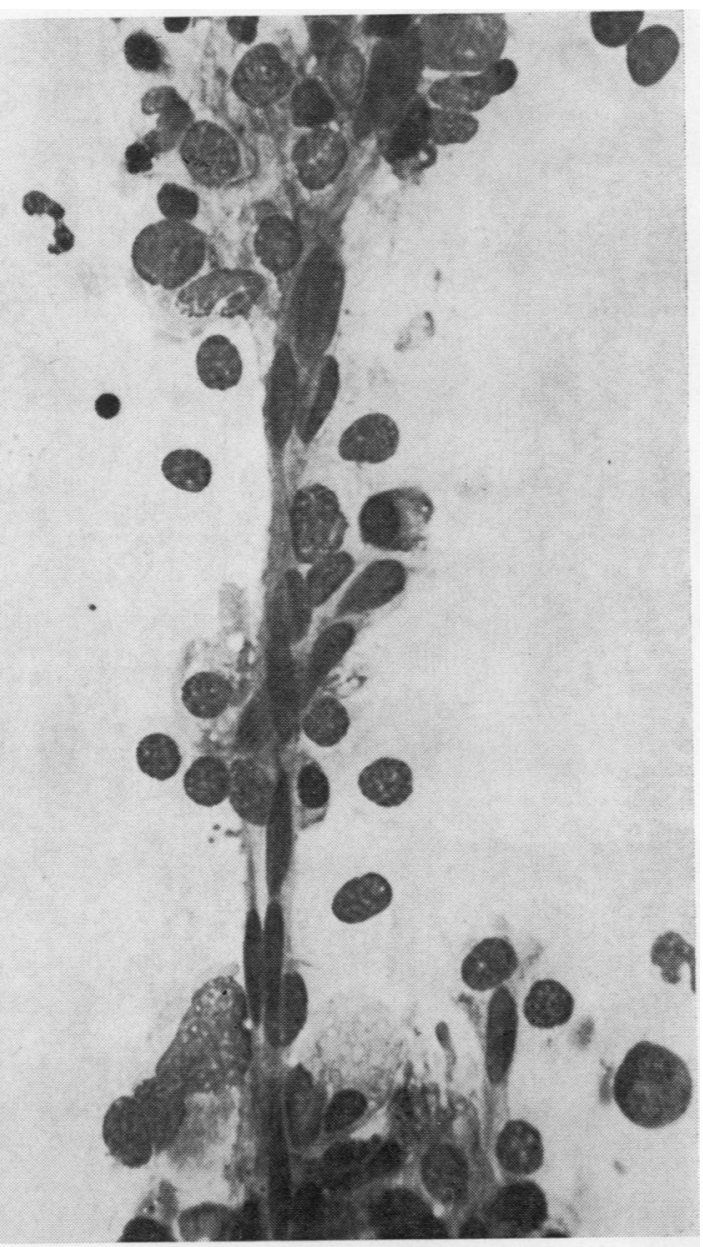

Fig 9 Plasma cells in apposition to a capillary $\times 600$.

absent. Scattered megakaryocytes were found in grade 3 marrows and normal numbers in marrows of grades 4-6.

\section{DYSERYTHROPOIESIS}

Dyserythropoiesis was present in every case. In a few only $5 \%$ of the erythroid cells were abnormal, but in the majority of cases more than half of the erythroid cells and in some cases as many as $90 \%$ were affected. Dyserythropoiesis occurred with all grades of hypocellularity and at any stage of cell development. The following features, some of which are illustrated in fig $10(\mathrm{a}-\mathrm{m})$, were especially noteworthy.

Megaloblastosis and asynchrony of maturation of nucleus and cytoplasm $(a, b)$ were the most frequent abnormalities. They occurred in every case and in some the majority of the erythroblasts were megaloblastic.

Binucleated erythroid cells (c) were present in about three-quarters of the cases. In a few they were an outstanding feature, but in the majority of cases only $1-3 \%$ of the normoblasts had double nuclei. Both early and late normoblasts were affected; in some of the binucleated cells asynchronous development of the paired nuclei was a striking feature.

Atypical mitotic figures (d, e) were found in both early and late erythroid cells in almost all cases.

Cytoplasmic connexions between erythroid cells of varying degrees of maturity $(h, i, f)$ were found in up to $5 \%$ of the erythroid cells both early and late. Occasionally there was a striking degree of asynchrony between cells thus joined. This abnormality was seen in $80 \%$ of the marrows.

Chromatin bridges between nuclei $(i, j)$ also occurred but they were much less frequent than cytoplasmic connexions.

In some preparations, extrusion of the nucleus was seen in relatively immature erythroblasts (f). Bare nuclei and cytoplasmic masses (g) (often basophilic) were also found.

In all marrows a small percentage of normoblasts showed degenerative changes in their nuclei $(\mathrm{k}, \mathrm{l}, \mathrm{m})$ -blurred nuclear outlines, irregular shapes, budding, and fragmentation.

In some cases vacuolations could be seen around the nucleus and occasionally between the nuclei of a binucleate erythroblast. More generalized cytoplasmic vacuolation was rare. Howell-Jolly bodies and basophilic stippling (m) were seen in $1-3 \%$ of the erythroblasts (mean $1.8 \%$ ) in about three-quarters of the cases. In some cases many features of dyserythropoiesis could be seen in a single field (fig 11).

\section{Discussion}

Whereas aplastic anaemia is characterized by a quantitative deficiency in cell production within the bone marrow, there is also frequently an associated qualitative defect in erythropoiesis (Lewis,1962). The present study has shown the extent to which morphological abnormalities occur.

The term dyserythropoiesis expresses both the kinetic and morphological aspects of abnormal erythropoiesis (Lewis and Verwilghen, 1972). Kinetically, there is ineffective erythropoiesis with intramedullary destruction of erythroblasts. Morphologically, dyserythropoiesis is characterized by asynchrony of maturation between nucleus and cytoplasm, mitotic abnormalities, nuclear lobulation, budding and fragmentation, binuclearity and multinuclearity with internuclear bridging and sometimes 

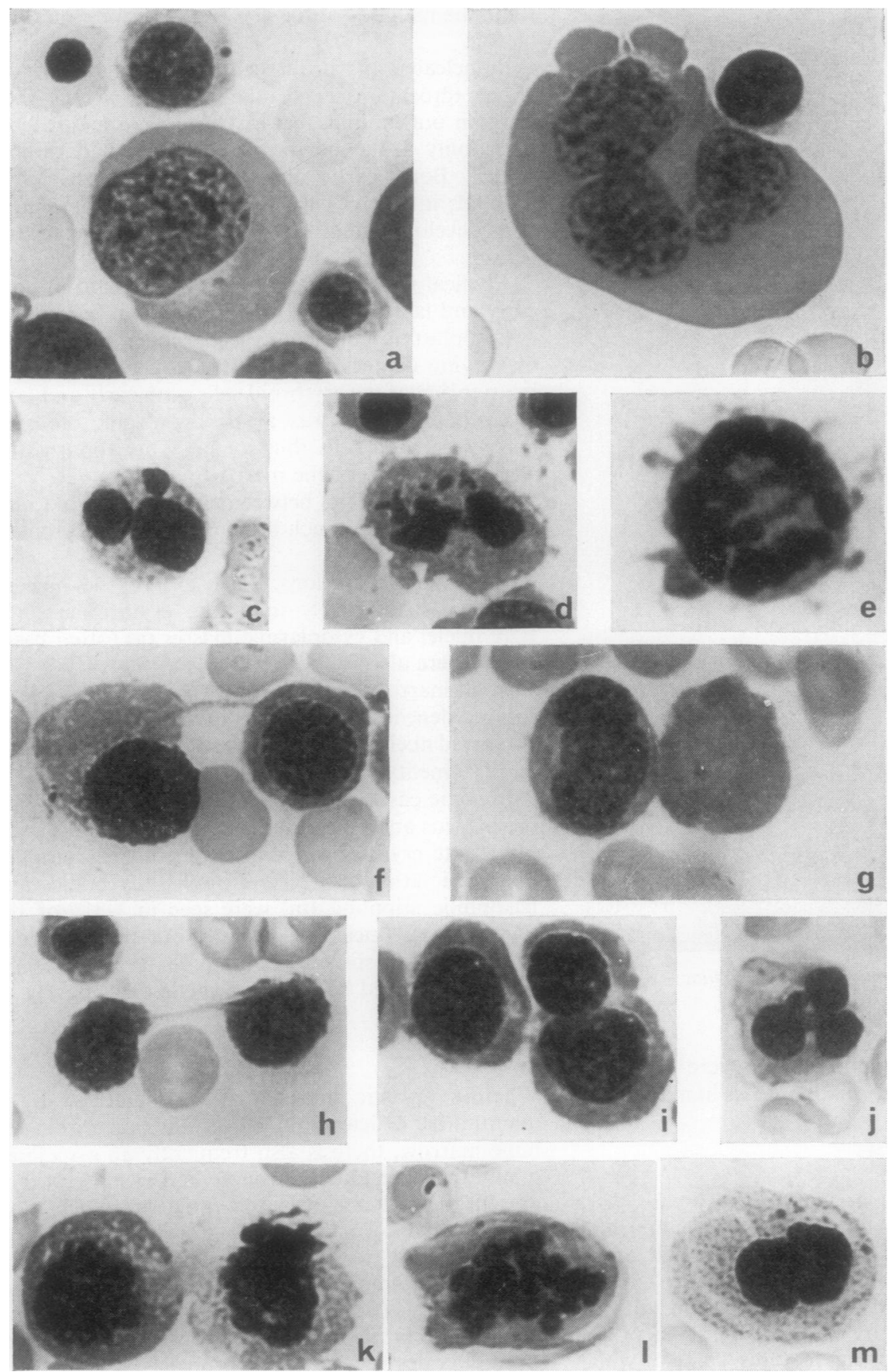

Fig 10 Features of dyserythropoiesis occurring in aplastic anaemia.

$\stackrel{\complement}{\stackrel{\complement}{\xi}}$

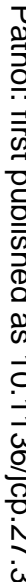

is

$\underline{\omega}$

号

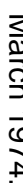

政

흉

$\underline{9}$

8ิ

을.

N

N

N

맘

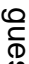

$\stackrel{5}{\longrightarrow}$

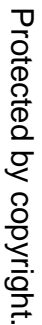




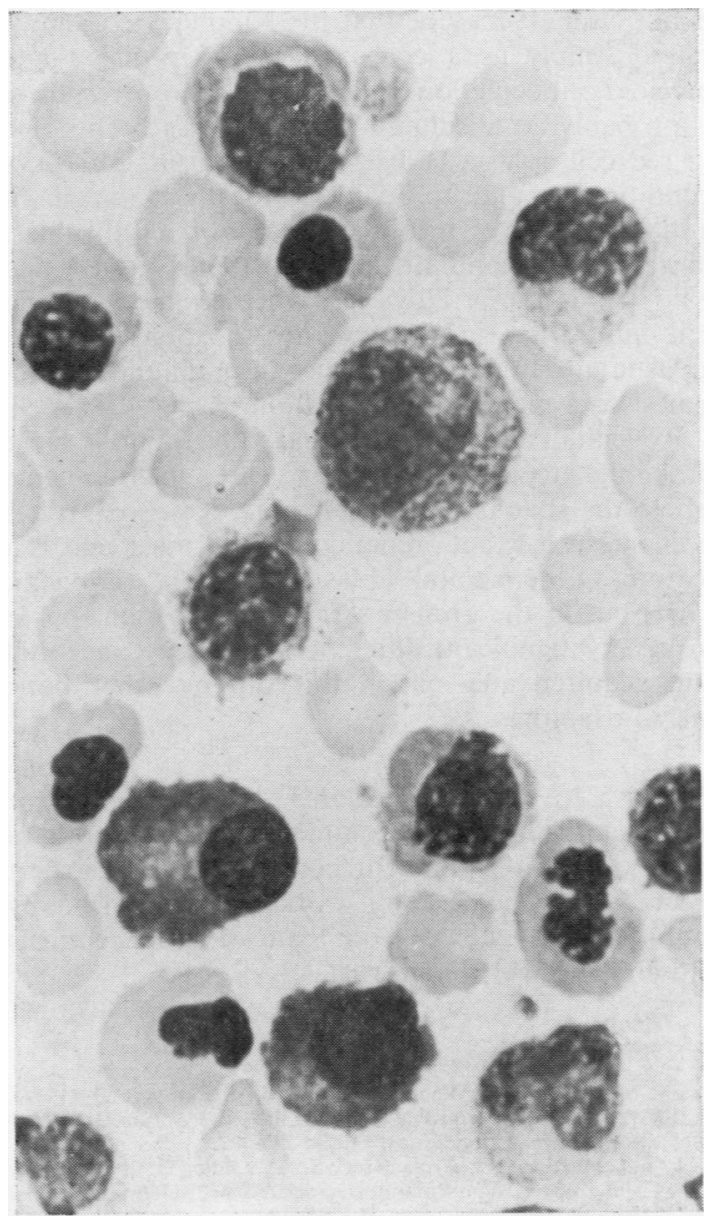

Fig 11 Photomicrograph of bone marrow from patient with aplastic anaemia showing various features of dyserythropoiesis $\times 1200$.

megaloblastic changes; cytoplasmic abnormalities include vacuolation and basophilic stippling and excessive deposition of iron in lysosomes or in mitochondria, and cytoplasmic bridging. Dyserythropoiesis of greater or lesser severity occurs in a wide range of diseases. Several types of congenital dyserythropoietic anaemias have been described and dyserythropoiesis is also evident in myelosclerosis, leukaemia, megaloblastic anaemias, irondeficiency anaemia, and in defects of iron utilization as found in acquired sideroblastic anaemias and infections.

From the static pictures of cells as seen in a marrow aspirate, it is difficult to deduce the dynamic processes involved in abnormal cytopoiesis; furthermore many of the morphological manifestations of dyserythropoiesis may occur as the result of a disturbance at any stage of erythropoiesis. In aplastic anaemia, some of the earliest recognizable erythroblasts show megaloblastic changes, indicating interference with DNA synthesis. Disturbances of the mechanism which regulates the cell cycle and normal mitosis results in multiple nuclei. Asynchronous maturation of each nucleus in a cell and premature extrusion from inadequately haemoglobinized cells are also consequences of defective cell differentiation. Other manifestations, such as nuclear budding and fragmentation, as well as cytoplasmic vacuolation, are probably degenerative. The pressure exerted on cells during extraction and smearing may lead to distortion, with stretching or rupture of intercellular connexions and displacement or fragmentation of intracellular structures. However, disturbance in protein synthesis may cause the cell to be more fragile and thus more easily damaged by these mechanical actions; it may also lead to a defective membrane which results in poikilocytosis and cell fragmentation and in increased uptake of anti-I (and anti-i) antibody (Lewis et al, 1970; Cooper, Hoffbrand, and Worlledge, 1968).

In relation to the dyserythropoiesis of aplastic anaemia, the effects on erythropioesis of certain chemicals may be relevant. Thus, benzene, a well recognized cause of aplastic anaemia (Goldwater, 1941; Aksoy, Dincol, Akgun, Erdem, and Dincol, 1971), inhibits DNA synthesis and cell division at the level of the stem cell; it may also cause chromosomal damage (Rondanelli, Gorini, Percorari, Trotta, and Colombi, 1961) and bone marrow fibrosis with structural alteration of the microenvironment and disruption of vessels (Knospe and Crosby, 1971). Chloramphenicol inhibits protein synthesis after attachment of amino acids to transfer RNA, by blocking the transfer of amino acid to ribosomes; haemoglobin synthesis is disturbed and excess iron accumulates in the mitochondria (Yunis and Bloomberg, 1964; Beck, Buehler, Armentrout, and Lüdin, 1972). Thus, toxic agents acting at different levels can bring about an apparently similar end result-aplastic anaemia and dyserythropoiesis.

In most cases of chronic acquired aplastic anaemia it is usually difficult to appreciate the sequence of events. The supposed causal agent may have destroyed a proportion of the stem cells and inflicted non-lethal injury on a proportion or on the whole of the remainder. Also, when remission occurs, the effects of damage to the original marrow population may persist, so that the marrow might contain a mixed population, namely, the progeny of unaffected stem cells which have survived to repopulate the 
bone marrow and descendants of non-lethally injured cells which manifest a persistent abnormality. This could explain the presence of both normal and disturbed erythropoiesis in the same preparation.

Atypical mitotic figures were seen in most cases of aplastic anaemia studied. This is of interest in view of the occurrence of leukaemia on the basis of a preexisting aplastic anaemia and of reports of leukaemia developing in patients with aplastic anaemia after androgen therapy (Delamore and Geary, 1971). As similar abnormalities were present in marrow films whether or not the patients had been receiving androgen therapy, this finding supports the suggestion that aplastic anaemia per se might give rise to an abnormal clone with a predisposition to leukaemia.

The variability of marrow cellularity in aplastic anaemia has been previously noted (Lewis, 1969). This is likely to result in unrepresentative sampling and the possibility that evaluation of a single bone marrow aspiration might lead to an erroneous diagnosis (fig 1). Furthermore, the appearance in aspirated material may differ from trephine sections; this may be due to residual marrow being less readily dislodged by aspiration in aplastic anaemia.

The relative proportion of different cell lines within the bone marrow aspirate varies greatly from case to case. Within each of the cell lines, cells of all stages of maturation were present, although in the myeloid series there was a relative preponderance of early cells. However, in contrast to refractory anaemia with myeloblastosis (Dreyfus, Sultan, Rochant, Salmon, Mannoni, Cartron, Boivin, and Galand, 1969) there was no absolute increase in myeloblasts. It has previously been shown that prognosis is related to the degree of neutropenia and thrombocytopenia in the blood (Lewis, 1965). The marrow granulocyte precursor cell content parallels the blood neutrophil count remarkably closely, so that prognosis is worse when the myeloid:erythroid ratio is reduced. The relationship of monocytopoiesis to granulopoiesis is fairly well established (Metcalf, 1971), and it has been reported that prognosis is poor when the blood monocyte count is less than 20/ $\mu 1$ (Twomey, Douglass, and Sharkey, 1973). In our study, monocytes were neither a prominent feature of the marrow nor remarkably deficient in any case and we were unable to confirm this observation.

A high proportion of lymphocytes in the marrow denotes a serious prognosis. This confirms the observations of Li, Alter, and Nathan (1972) who found in 58 children with acquired aplastic anaemia that death occurred in all cases with marrow lymphocyte counts of more than $85 \%$, whereas the mortality was $60 \%$ in the cases with lower lymphocyte counts. The significance of lymphocyte increase is not clear. It may be that the lymphocyte count is raised simply as a consequence of erythroid and myeloid cell depletion. In other cases, however, there is probably an absolute increase, as has been noted in red cell aplasia (Böttiger and Rausing, 1972), a condition thought to be due to the development of antibodies to erythropoietin and/or erythroblast nuclei (Jepson and Lowenstein, 1966; Krantz and Kao, 1967, 1969). However, whether the lymphoid cell infiltration in the marrow in some cases of aplastic anaemia implies an autoimmune pathogenesis is a matter for speculation.

Reticulum and mast cells tend to be found in close proximity to each other, at least, in fragments where the spatial relationships are preserved. It has been suggested that preponderance of mast cells is a feature of congenital aplastic anaemia (Fanconi, 1964) but in the present series there do not appear to be any significant differences between congenital and acquired anaemia in this or any other bone marrow features.

We wish to thank Professor J. V. Dacie FRS for advice and his critical comments. We are grateful to Miss N. Kiley BSc for considerable and expert technical assistance. This work was supported by grants (to S. M. Lewis) from Syntex Pharmaceuticals Ltd and the Wellcome Trust.

\section{References}

Aksoy, M., Dincol, K., Akgun, T., Erdem, S., and Dincol, G. (1971) Haematological effects of chronic benzene poisoning in 217 workers. Brit. J. indust. Med., 28, 296-302.

Beck, E.A., Beuhler, F., Armentrout, S. A., Lüdin, H. (1972). Early hematological abnormalities associated with chloramphenicol therapy. Helv. med. Acta. 36, 295-306.

Böttiger, L. E., and Rausing, A. (1972). Pure red cell anemia: immunosuppressive treatment. Ann. intern. med., 76, 593-597.

Cooper, A. G., Hoffbrand, A. V., and Worlledge, S. M. (1968). Increased agglutinability by anti-i of red cells in sideroblastic and megaloblastic anaemia. Brit. J. Haemat., 15, 381-387.

Dacie, J. V., and Lewis, S. M. (1968). Practical Haematology, 4th ed. Churchill, London.

Delamore, I. W., and Geary, C. G. (1971). Aplastic anaemia, acute myeloblastic leukaemia and oxymetholone. Brit. med. J., 2, 743-745.

Dreyfus, B., Sultan, C., Rochant, H., Salmon, C., Mannoni, P., Cartron, J. P., Boivin, P., and Galand, C. (1969). Anomalies of blood group antigens and erythrocyte enzymes in two types of chronic refractory anaemia. Brit. J. Haemat., 16, 303-312.

Fanconi, G. (1964). Die familiäre panmyelopathie. Schweiz. med. Wschr., 94, 1309-1318.

Goldwater, L. J. (1941). Disturbances in the blood following exposure to benzol. J. lab. clin. Med., 26, 957-973.

Jepson, J. H., and Lowenstein, L. (1966). Inhibition of erythropoiesis by a factor present in the plasma of patients with erythroblastopenia. Blood, 27, 425-434.

Knospe, W. H., and Crosby, W. H. (1971). Aplastic anaemia: a disorder of the bone-marrow sinusoidal microcirculation rather than stem-cell failure? Lancet, 1, 20-22.

Krantz, S. B., and Kao, V. (1967). Studies on red cell aplasia: I Demonstration of a plasma inhibitor to heme synthesis and an antibody to erythroblast nuclei. Proc. Nat. Acad. Sci. (Wash)., 58, 493-500.

Krantz, S. B., and Kao, V. (1969). Studies in red cell aplasia. II. Report of a second patient with an antibody to erythroblast nuclei 
and a remission after immunosuppressive therapy. Blood, 34, 1-13.

Lewis, S. M. (1962). Red-cell abnormalities and haemolysis in aplastic anaemia. Brit. J. Haemat., 8, 322-334.

Lewis, S. M. (1965). Course and prognosis in aplastic anaemia. Brit. med. J., 1, 1027-1031.

Lewis, S. M. (1969). Aplastic anaemia : problems of diagnosis and of treatment. J. Roy. Coll. Phycns. London., 3, 253-264.

Lewis, S. M., and Dacie, J. V. (1967). The aplastic anaemia-paroxysmal nocturnal haemoglobinuria syndrome. Brit. J. Haemat., 13, 236-251.

Lewis, S. M., Grammaticos, P., and Dacie, J. V. (1970). Lysis by anti-I in dyserythropoietic anaemias: role of increased uptake of antibody. Brit. J. Haemat., 18, 465-474.

Lewis, S. M., and Verwilghen, R. L. (1972). Annotation: Dysery- thropoiesis and dyserythropoietic anaemia. Brit. J. Haemat., 23, 1-4.

Lewis, S. M., and Verwilghen, R. L. (1973). Dyserythropoiesis and dyserythropoietic anaemia. Progr. Hemat., 8,

Li, F. P., Alter, B. P., and Nathan, D. G. (1972). The mortality of acquired aplastic anemia in children. Blood, 40, 153-162.

Metcalf, D. (1971). Transformation of granulocytes to macrophages in bone marrow colonies in vitro. J. cell Physiol., 77, 277-280.

Rondanelli, E. G., Gorini, P., Pecorari, D., Trotta, N., and Colombi, R. (1961). Effects du benzène sur la mitose érythroblastique. Investigations à la microcinematographie en contraste de phase Acta haemat. (Basel)., 26, 281-302.

Twomey, J. J., Douglass, C. C., and Sharkey, O., Jr. (1973). The monocytopenia of aplastic anemia. Blood, 41, 187-195.

Yunis, A. A., and Bloomberg, G. R. (1964). Chloramphenicol toxicity: clinical features and pathogenesis. Progr. Hemat., 4, 138-159.

\section{The February 1974 Issue}

\section{THE FEBRUARY 1974 ISSUE CONTAINS THE FOLLOWING PAPERS}

A reappraisal of the antibacterial action of cotrimoxazole in vitro EVELYN L. LEWIS, J. D. ANDERSON, AND R. W. LACEY

Aeruginocine typing of Pseudomonas aeruginosa SHRINIWAS

A symptomatic infection with EB virus R. N. P. SUTTON, S. D. MARSTON, E. J. P. ALMOND, K. REYNOLDS, AND F. J. POUNDS

Counting cells in cerebrospinal fluid collected directly on membrane filters F. BURECHAILO AND T. A. CUNNINGHAM

The cellular composition of the granulocyte series in the normal human bone marrow according to the volume of the sample C. DRESCH, A. FAILLE, O. POIRIER, AND J. KADOUCHE

Red face and reduced plasma volume SYLVIA $w$. DAVIES, EVELINE GLYNNE-JONES, AND E. PATRICIA LEWIS

Effect of phytohaemagglutinin in the leucocyte migration inhibition test as a measure of cellmediated immunity WARWICK L. MORISON

The detection of autoantibodies with an enzyme bridge method P. M. FORD AND P. J. STOWARD

Arthritis, deformities, and runting in C5-deficient mice injected with human rheumatoid arthritis synovium J. F. S. CROCKER, T. GHOSE, K. ROZEE, J. WOODBURY, AND B. STEVENSON

Hepatitis B antigen (HBAg) and its antibody (HBAb) in hospital patients R. W. PAYNE, A. BARR, AND J. WALLACE
The effect of serum protein concentrations on the specificity of the radioimmunoassay of carcinoembryonic antigen in malignant neoplasia and non-neoplastic disease J. M. CRAWLEY, B. E. NORTHAM, J. P. G. KING, J. C. LEONARD, S. N. BOOTH, AND P. W. DYKES

Steroid excretion and metabolism by gonadal tissue from a subject with testicular feminization syndrome E. LOCKWOOD, P. C. GHOSH, G. W. PENNINGTON, AND R. TIPTON

An assessment of serum acid and alkaline phosphatase determinations in prostatic cancer with a clinical validation of an acid phosphatase assay utilizing adenosine $\mathbf{3}^{\prime}$-monophosphate as substrate DAVID M. GOLDBERG AND GRAHAM ELLIS

A rapid method for determining decarboxylase and dihydrolase activity $\mathrm{K}$. BROOKS AND T. SODEMAN

Evaluation of new kits for the assessment in vitro of thyroid function by determination of serum total thyroxine, free TBG capacity, and free thyroxine index using Sephadex G-25 and ${ }^{125}$ I-labelled triiodothyronine and thyroxine P. J. N. HOWARTH AND C. G. MCKERRON

Evans blue as counterstain in the demonstration of muscle antibodies by immunofluorescence in myasthenia gravis o. CLOSS AND J. A. AARLI

\section{Technical method}

Modification of the urease method for gentamicin assays P. R. BOURNE, I. PHILLIPS, AND S. E. SMITH

Letters to the Editor

Book reviews

Notices

Copies are still available and may be obtained from the PUBLISHING MANAGER, BRITISH MEDICAL ASSOCIATION, TAVISTOCK SQUARE, LONDON, WC1H 9JR, price $£ 1.05$. 